Paediatr Perinatal Drug Ther 2000;4(2):71-4.

7. Bonati M, Pandolfini C, Rossi V, Santoro E, Arnau De Bolos JM, Carreras ID, et al. Launch of a European paediatric clinical trials register. Paediatr Perinatal Drug Ther 2004;6(1):38-9.

DOI:10.1503/cmaj.1050001

\section{Cardiovascular risk in patients with type 2 diabetes}

$\mathrm{T}$ here is no doubt that aggressive control of common risk factors is of paramount importance in the management of diabetic patients with atherosclerotic disease to prevent cardiovascular morbidity and mortality. In assessing management of such patients, Lauren Brown and associates ${ }^{1}$ identified the study cohort between 1991 and 1996 and followed the patients until 2000; however, the evidence for the standard therapies they evaluated (regarding antiplatelet agents, ${ }^{2}$ angiotensin-converting enzyme [ACE] inhibitors ${ }^{3}$ and statins ${ }^{4}$ ) did not become available until at least 2000. In other words, evidence published during or after the year 2000 was applied to data collected up to 2000; thus, it is no surprise that management was suboptimal relative to current recommendations.

It would have been preferable for the authors to have used the 1998 guidelines for management of diabetes ${ }^{5}$ in evaluating the care provided to these patients. I acknowledge that their findings would probably have been similar, as it takes a few years to implement such guidelines (by which time they may have been changed or be undergoing revision). None of the therapies listed above was strongly recommended for cardiovascular protection in the 1998 guidelines. In fact, the UK Prospective Diabetes Study, ${ }^{6}$ published at the same time, highlighted the importance of effectively controlling both blood glucose and blood pressure to improve microvascular and macrovascular complications and did not favour one agent over the other ( $\beta$-blocker versus $\mathrm{ACE}$ inhibitor).

Since then, however, evidence has accumulated, and the 2003 Canadian guidelines $^{7}$ make appropriate recommendations about these therapies.

Malvinder Parmar

Associate Professor, Medicine

Northern Ontario School of Medicine

Laurentian and Lakehead Universities

Sudbury and Thunder Bay, Ont.

\section{References}

1. Brown LC, Johnson JA, Majumdar SR, Tsuyuki RT, McAlister FA. Evidence of suboptimal management of cardiovascular risk in patients with type 2 diabetes mellitus and symptomatic atherosclerosis. CMAF 2004;171(10):1189-92.

2. Antithrombotic Trialists' Collaboration. Collaborative meta-analysis of randomised trials of antiplatelet therapy for prevention of death, myocardial infarction, and stroke in high risk patients [published erratum in BM7 2002; 324:141]. BM7 2002;324:71-86.

3. Heart Outcomes Prevention Evaluation (HOPE) Study Investigators. Effects of ramipril on cardiovascular and microvascular outcomes in people with diabetes mellitus: results of the HOPE study and MICRO-HOPE substudy [published erratum in Lancet 2000;356:860]. Lancet 2000;355:253-9.

4. Heart Protection Study Collaborative Group. MRC/BHF Heart Protection Study of cholesterol lowering with simvastatin in 5963 people with diabetes: a randomized placebo-controlled trial. Lancet 2003;361:2005-16.

5. Meltzer S, Leiter L, Daneman D, Gerstein HC, Lau D, Ludwig S, et al. 1998 clinical practice guidelines for the management of diabetes in Canada. CMA7 1998;159(8 Suppl):S1-29.

6. UK Prospective Diabetes Study Group. Tight blood pressure control and risk of macrovascular and microvascular complications in type 2 diabetes. UKPDS 38. BM7 1998;317:703-13.

7. Canadian Diabetes Association. 2003 clinical practice guidelines for the prevention and management of diabetes in Canada. Can 7 Diabetes 2003;27(Suppl 2):S1-140.

Competing interests: None declared.

DOI:10.1503/cmaj.1041725

$\mathrm{L}$ auren Brown and associates ${ }^{1}$ observed low use of therapies with proven benefit for the prevention of

Table 1: Use of proven cardioprotective agents in a cohort of high-risk patients: preliminary results

\begin{tabular}{|c|c|c|c|c|c|c|}
\hline \multirow[b]{2}{*}{ Agent } & \multicolumn{3}{|c|}{$\begin{array}{l}\text { No. (and \%) of high-risk patients } \\
\qquad n=407\end{array}$} & \multicolumn{3}{|c|}{$\begin{array}{l}\text { No. (and \%) of diabetic patients* } \\
\qquad n=178\end{array}$} \\
\hline & $\begin{array}{l}\text { First visit } \\
n=407\end{array}$ & $\begin{array}{c}\text { Most recent } \\
\text { visit } \\
n=402\end{array}$ & $p$ value & $\begin{array}{l}\text { With CAD } \\
\quad n=54\end{array}$ & $\begin{array}{c}\text { Without } \\
\text { CAD } \\
n=124\end{array}$ & $p$ value \\
\hline ASA & $194(48)$ & 302 (75) & $<0.001$ & $39(72)$ & $81(65)$ & 0.22 \\
\hline Statins & 158 (39) & $328(82)$ & $<0.001$ & $44(81)$ & $99(80)$ & 0.80 \\
\hline$\beta$-Blockers & $108(27)$ & $127(32)$ & 0.11 & $23(43)$ & $13(10)$ & $<0.001$ \\
\hline ACE inhibitors & 143 & $284(71)$ & $<0.001$ & $45(83)$ & $80(65)$ & 0.012 \\
\hline
\end{tabular}

$\mathrm{CAD}=$ coronary artery disease, $\mathrm{ASA}=$ acetylsalicylic acid, $\mathrm{ACE}=$ angiotensin-converting enzyme.

*Data obtained during most recent visit. cardiovascular events in patients with type 2 diabetes, both with and without atherosclerotic disease. We are conducting a similar study analyzing use of acetylsalicylic acid (ASA), statins, $\beta$ blockers and angiotensin-converting enzyme (ACE) inhibitors (or equivalent) in a cohort of 407 high-risk patients attending the Lipid/Cardiovascular Risk Reduction Clinic at St. Paul's Hospital in Vancouver. These patients have a history of vascular disease (coronary, peripheral or cerebral) with or without diabetes.

Data on the patients' lipid profile and use of the 4 medications at the time of the initial visit to the clinic (between 1984 and 2004) and their most recent visit (between November 2003 and July 2004) have been collected (Table 1). The use of these medications will also be prospectively evaluated at the next scheduled visit.

We are also trying to examine differences in medication use in a subgroup of 178 patients with diabetes from the same cohort: 54 with established coronary artery disease (CAD) and 124 without clinical evidence of CAD. Preliminary data were obtained from the most recent follow-up visits (with an average of 60 months between the first and the most recent visit). We found no significant differences in the use of ASA and statins between the 2 groups; however, the rate of treatment with $\beta$-blockers and ACE inhibitors was significantly higher among patients with CAD than among those without CAD. Although the difference in $\beta$ blocker use was not unexpected, we 
were surprised by the low use of ACE inhibitors or equivalent for patients who had diabetes but no clinical evidence of CAD.

These preliminary results indicate that there is room for improvement in implementing treatment guidelines in clinical practice. The overall use of cardioprotective medications was suboptimal at the initial visit, although use had increased significantly by the time of the most recent visit (Table 1). However, the use of ACE inhibitors remained suboptimal among diabetic patients without CAD, a result similar to the data presented by Brown and associates. ${ }^{1}$ We agree that multidisciplinary cardiovascular risk reduction programs are needed to improve quality of care in high-risk patients.

\section{Miriam Shanks}

University of Alberta Hospital

Edmonton, Alta.

Daniel T. Holmes

Luba Cermakova

Jiri Frohlich

Lipid/Cardiovascular Risk Reduction Clinic

St. Paul's Hospital

Vancouver, BC

\section{Reference}

1. Brown LC, Johnson JA, Majumdar SR, Tsuyuki RT, McAlister FA. Evidence of suboptimal management of cardiovascular risk in patients with type 2 diabetes mellitus and symptomatic atherosclerosis. CMA7 2004;171(10):1189-92.

Competing interests: None declared.

DOI:10.1503/cmaj.1050049

\section{C. difficile: Will lessons be learned?}

$\mathrm{L}$ aura Eggertson" reports that "there were 7004 cases of [Clostridium] difficile across Quebec from Apr. 1, 2003, to Mar. 31, 2004, and 1270 people died." Additional data in her article reveal a staggering increase in both morbidity and mortality due to $C$. difficile from 2001 to $2003,{ }^{1}$ yet the provincial government only recently intervened with policies to aggressively control the outbreak. Moreover, some health care professionals have reported a lack of sufficient resources to effectively control the outbreak. ${ }^{2}$ This state of affairs raises 2 issues: first, how health care institutions effectively intervene when a pathogen manifests in a community and, second, the allocation of resources to achieve desired social goals.

The fact that, until recently, reporting of hospital-acquired infections to health care authorities was not required points to both structural and procedural shortcomings within our health care institutions. The recent establishment of province-wide surveillance and infection-control committees is intended to rectify the structural deficiencies, although the effectiveness of these measures remains unknown. In addition, procedural interventions appear to have been underused, both clinically and interpersonally. Clinically, health care professionals should have been informed by a provincial nosocomial infection control committee about the technical means of controlling the outbreak. This advice should have been based on the best evidence available and should have been provided as soon as possible after the increase in incidence was noted. ${ }^{3-5}$ At an interpersonal level, patients or their representatives should have been informed of the increased risks and patient groups should have been engaged in consultation and decision-making.

Yet these structural and procedural interventions cannot be undertaken without the addition of the resources needed for their implementation. If hospitals have to redirect existing scarce resources from other services to combat C. difficile, overall quality of care could decline.

But the saddest lesson from the $C$. difficile outbreak has been exposure of the lack of planning and coordination in the face of a virulent form of a known infection. I hope the lessons of the $C$. difficile epidemic serve as a grave warning in case of future outbreaks of new pathogens.

\section{Joseph Erban \\ Member}

Clinical Ethics Committee

Sir Mortimer B. Davis - Jewish General

Hospital

Montréal, Que.

\section{References}

1. Eggertson L. C. difficile: by the numbers. CMAf 2004;171(11):1331-2.

2. Minister refutes doctor's $C$. difficile complaints [news article on Internet]. Montréal: CBC; 2004. Available: http://montreal.cbc.ca/regional/servlet $/$ View? filename $=q c \_c d i f f 20041115$ (accessed 2004 Nov 16).

3. Frith M. Hygiene crackdown to tackle rise of hospital superbugs. The Independent Online Edition [London] 2004 Jul 12. Available: http://news .independent.co.uk/uk/health_medical/story.jsp ?story $=540149$ (accessed 2004 Jul 12). Subscription required to access full article content online.

4. Bourn J. Improving patient care by reducing the risk of hospital acquired infection: a progress report. Report by the Comptroller and Auditor General. HC 876 session 2003-2004. London (UK): National Audit Office; 2004. Available: www.nao .org.uk/publications/nao_reports/03-04/0304876 .pdf (accessed 2005 Mar 9).

5. Guidelines for environmental infection control in health-care facilities. Atlanta: US Department of Health and Human Services, Centers for Disease Control and Prevention; 2003. Available: www .cdc.gov/ncidod/hip/enviro/Enviro_guide_03.pdf (accessed 2005 Feb 3).

DOI:10.1503/cmaj.1041743

\section{Influenza vaccine for all?}

Tfind it interesting that, a few weeks after celebrating the achievements of the Cochrane Collaboration, ${ }^{1}$ CMAf published a systematic review ${ }^{2}$ and a recommendation statement from the 